\title{
GIANT IMPACT INDUCED ATMOSPHERIC BLOW-OFF
}

\author{
Thomas J. Ahrens, Andy H. Shen, and Sidao Ni \\ Seismological Laboratory, California Institute of Technology, Mail Code 252-21, Pasadena, CA 91125.
}

\begin{abstract}
Previous calculations indicate that the Earth suffered impacts from objects up to Mars size. Such a giant impact may have produced a temporary ejecta-based ring that accreted to form the Moon. To simulate the surface waves from such events we approximated the cratering source as a buried pressurized sphere. For a $10^{27} \mathrm{~J}$ impactor we calculated the resulting surface wave using the mode summation method of Sato et al. [1]. For such an impact, the solid Earth free-surface velocity above, and antipodal to, the source achieves 2.6 and $1.9 \mathrm{~km} / \mathrm{s}$. Such large ground motions pump the atmosphere and result in upward particle motions which cause the atmosphere to be accelerated to excess of the escape velocity $(11.2 \mathrm{~km} / \mathrm{s})$ at high altitudes. For a $1.3 \times 10^{32} \mathrm{~J}$ Moon-forming impact we calculate that $\sim 50 \%$ of the Earth's atmosphere is accelerated to escape.
\end{abstract}

\section{INTRODUCTION}

The Safronov [2], Wetherill [3], and Kaula [4] (SWK) scenario of accretion of the terrestrial planets (Mercury, Venus, Earth, and Mars) from planetesimals in orbit around the Sun via mutual gravitational attraction and impact accretion has now become widely accepted. The planetesimals themselves are widely envisioned as being represented by the presently observed classes of meteorites: stony, iron, and primitive (e.g., chondrites). These contain up to $10 \%$ planetary volatiles $\left(\mathrm{H}_{2} \mathrm{O}, \mathrm{CO}_{2}, \mathrm{NH}_{3}\right.$, and $\mathrm{CH}_{4}$, and $\mathrm{He}, \mathrm{Ne}$, $\mathrm{Ar}, \mathrm{Kr}$, and $\mathrm{Xe}$ ). Thus, an array of planetesimals, corresponding to the above meteorite types, accreted to form the iron-rich metallic cores, silicate mantles, and volatile-bearing crusts, oceans, and atmospheres of the planets. Publication of Smith and Terrile's [5] image of a $10^{2} \mathrm{AU}$ radius, gas and dust disk orbiting a nearby main sequence star, Beta Pictoris, now, presumably, forming another solar system solidified acceptance of the SWK model. Baggeley's [6] observation that the Beta Pictoris disk emits impact ejecta, and is the most concentrated source of extrastellar meteorites in the sky, further supports the SWK model of planetary impact accretion.

Abe and Matsui [7] applied the SWK model and shock data [8] for impact dehydration of waterbearing minerals (e.g. serpentine, $\mathrm{Mg}_{3} \mathrm{Si}_{2} \mathrm{O}_{7} \cdot \mathrm{H}_{2} \mathrm{O}$ contained in planetesimals) and demonstrated that when the proto-Earth had accreted to a radius of $\sim 2000 \mathrm{~km}$, a substantial ( 200 bar) $\mathrm{H}_{2} \mathrm{O}$-rich primordial atmosphere formed and surrounded the still growing planet. Continued accretional impacts induced a molten rock (magma) ocean which retained impact heat on account of an infraredopaque overlying $\mathrm{H}_{2} \mathrm{O}-\mathrm{CO}_{2}$-rich atmosphere. The Abe and Matsui model thus predicts that the Earth accreted from lunar to its present mass with a $\sim 1500 \mathrm{~K}$ (molten $\mathrm{H}_{2} \mathrm{O}$-rich basalt) surface layer. Impact-induced melted iron passed through the partially melted silicate mantle to form the core, whereas many of the atmospheric components were dissolved in the solid and molten crust or remained in the primordial atmosphere.

Recent studies [9] of the decay of short lived isotope ( $9 \times 10^{6}$ year, half life) ${ }^{182} \mathrm{Hf}$ to ${ }^{182} \mathrm{~W}$ in lunar and Earth rocks indicate that the accretion of the metallic core of the Earth was complete within 30 million years after formation of the accreting 
pre-planetary disk. The relative abundance of ${ }^{182} \mathrm{~W}$ in lunar rocks indicates that the Moon also formed some 25 to 33 million years after planetary accretion began.

Ahrens [10] suggested that after the formation of the Abe and Matsui primordial atmosphere, larger and larger impacts occurred on the Earth. As a result, the primordial atmosphere may have been seriously eroded or even blown away. Thus, the Earth's present atmosphere may be a small remnant of the primordial atmosphere. Accretion calculations indicate the largest giant impact on the Earth was produced by Mars-sized planetesimals (energies, $4 \times 10^{31}$ to $4 \times 10^{32} \mathrm{~J}$ ). Ejecta from such impacts could be launched such that a debris ring orbited the Earth. This ring may later have accreted to form the Moon. At issue is whether such large impacts could blow-off all, or a fraction of, the proto-atmosphere to greater than Earth escape velocity $(11.2 \mathrm{~km} / \mathrm{s})$. Previous onedimensional modeling of such events (Ahrens [11], Chen and Ahrens [12], and Genda and Abe [13]) was recently discussed by Melosh [14].

When an impactor of radius, $a$, strikes a planet with an atmosphere of scale height $(h)$, when $a<h$, atmosphere is lost from the planet when a portion of it is accelerated to velocities exceeding the escape velocity, $\mathrm{V}_{\text {esc }}$ in the vicinity of the impact $[15,16]$. The present paper is concerned with the giant impact case when $a>h$, and a strong shock wave is driven through the planet. In this case, the solid Earth drives a shock wave into the overlying atmosphere.

\section{METHOD}

To approximate the peak outward motion of a planet from a large impact, $\mathrm{Ni}$ and Ahrens [17] assumed the impact source could be approximated by a buried spherical source region (Fig. 1). They assumed an elastic Earth with a mean density of $\rho_{0}$ $=5.51 \mathrm{Mg} / \mathrm{m}^{3}$. As a baseline they assumed a source radius of 0.02 , centered at 0.96 . Thus 4.78 $\mathrm{x} 10^{19} \mathrm{~kg}$ of rock is pressurized to $\mathrm{P}_{0}=\mathrm{K}_{\mathrm{s}}=5.51$ GPa. This bulk modulus, and the mean Earth density, then define a mean bulk sound velocity of $10 \mathrm{~km} / \mathrm{s}$. The initial pressures at, $\mathrm{P}_{0}$, applied at $\mathrm{t}=$ 0 yields an energy density of:

$$
\Delta \mathrm{E}=\mathrm{K}_{\mathrm{s}} /(\rho \gamma)
$$

Here $\gamma=2$ is the Grüneisen ratio within the source region. Thus, an energy density of $5.0 \times 10^{6} \mathrm{~J} / \mathrm{kg}$ in source region and a total energy of $2.39 \times 10^{27} \mathrm{~J}$ is obtained. We overestimate the effective bulk modulus of the Earth to compensate, in part, for our neglect of the restoring forces for both gravity and shear modulus.

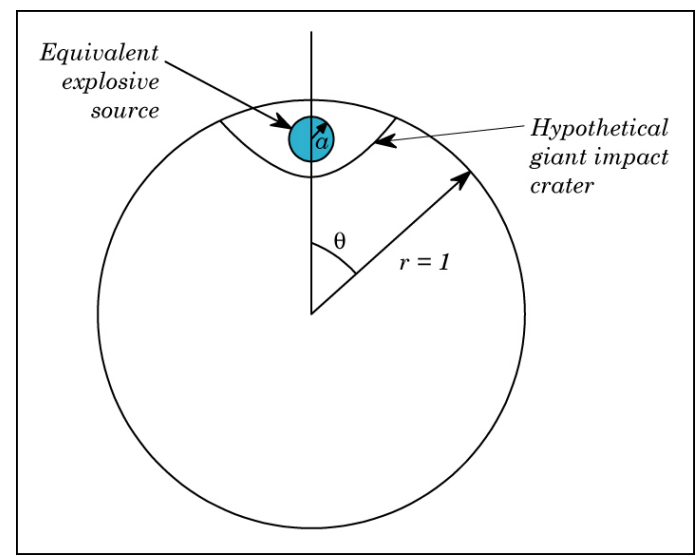

FIGURE 1. Model impact source is a fluid sphere of radius, a, pressurized to $\mathrm{P}_{0}$ at $\mathrm{t}=0$. Here, $\mathrm{a}=0.02$, centered at radius $r=0.96$

The surface motion resulting from the application of $\mathrm{P}_{0}$, at $\mathrm{t}=0$, is obtained using a normal mode summation method [1]. This yields the free-surface velocity history as a sum of terms involving products of spherical Bessel functions and Legendre polynomials [17]. The source motions at a series of 19 stations at $10^{\circ}$ intervals around the spherical Earth are given in Fig. 2.

\section{RESULTS}

The particle velocities of Fig. 2 demonstrate three maxima in amplitude. These affect air wave propagation driven into the atmosphere immediately above the station. As expected, the peak particle amplitude immediately above the source is a maximum $(2.6 \mathrm{~km} / \mathrm{s})$, maxima $(0.081$ $\mathrm{km} / \mathrm{sec}$ ) also occur at $\pm 70^{\circ}$ (corresponding to 
super-position of the direct $\mathrm{P}$ and quasi-surface wave). Antipodal focusing of the surface wave yields $1.90 \mathrm{~km} / \mathrm{s}$ at $180^{\circ}$. Previously, Chen and Ahrens [12] demonstrated that a ground motion $\sim 2$ $\mathrm{km} / \mathrm{s}$ induced atmospheric loss of $10^{-3}$ of the Earth's atmosphere. Genda and Abe [13] demonstrated that Chen and Ahrens' result was very insensitive to surprisingly large variation in atmospheric models.

Gas loss from atmospheres of Earth, Venus, and Mars (Table 1), above each of 19 stations was calculated using the modified WONDY program (Chen and Ahrens [12], Table 2). Because of the

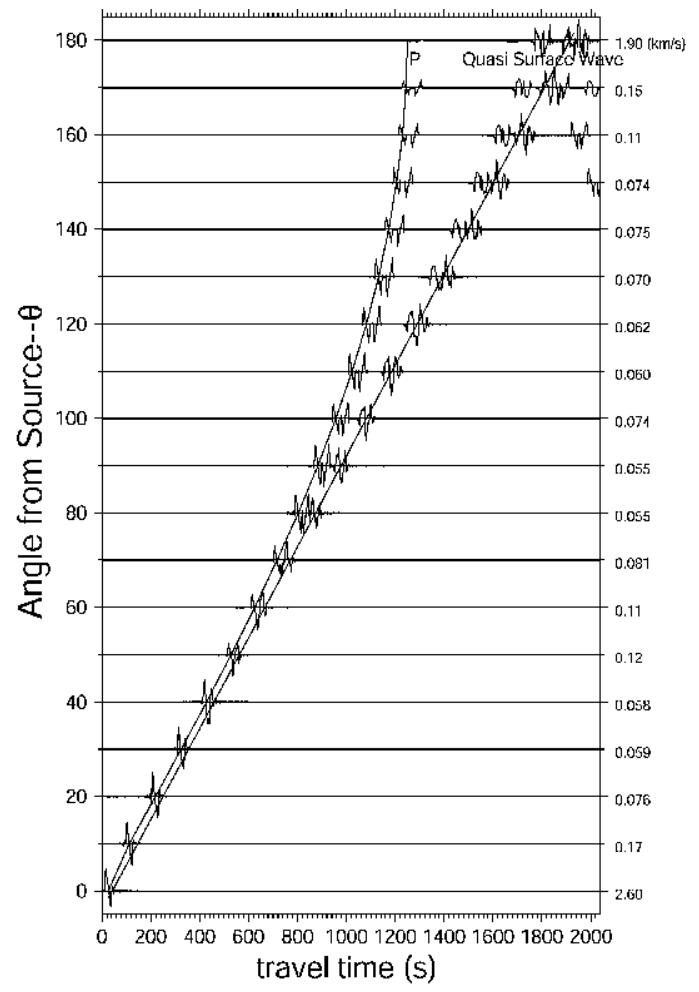

FIGURE 2. Free-surface particle velocity vs. time for different angles (source, $2.4 \times 10^{27} \mathrm{~J}$ ). Curves indicate geometrical arrival of $\mathrm{P}$ wave and quasi-surface wave. Peak particle velocity values (achieved by either the P- or Quasi-Surface Wave) are listed along right hand side.

finite tensile strength of planetary solids (Genda and Abe [13]), the peak amplitudes (given in Fig. 2) was assumed in the atmospheric calculation.
The excitation in WONDY assumed only the peak ground motion, $\mathrm{V}_{\mathrm{fs}}$ peak, at each station, and decreased with time via gravitational deceleration

$$
\mathrm{v}_{\mathrm{fs}}=-\mathrm{GM} \int_{0}^{\mathrm{v}_{\mathrm{fs}} \text { peak }} \frac{\mathrm{dt}}{\mathrm{R}^{2}}
$$

where $\mathrm{G}$ is the gravitational constant, $6.67 \times 10^{-11}$ $\mathrm{kg}^{-1} \mathrm{~m}^{3} / \mathrm{s}^{2}$ and $\mathrm{M}$ is planetary mass (Table 1 ). Scaling the peak free surface velocities, $\mathrm{v}_{\text {fs peak }}$, at energy, $\mathrm{E}_{0}=2.4 \times 10^{27} \mathrm{~J}$, hydrodynamically to other energies, E, yields:

$$
\mathrm{v}_{\mathrm{fs}}=\mathrm{v}_{\mathrm{fs} \text { peak }} \sqrt{\mathrm{E} / \mathrm{E}_{0}}
$$

and integrated over the Earth yields Fig. 3. Notably, peaks in atmospheric blow-offs occur at positions at $0^{\circ}, 70^{\circ}$ and $180^{\circ}$ as discussed above. As can be seen, Mars-sized impactors (Fig. 3) of $\sim 8 \times 10^{31} \mathrm{~J}$ will cause total atmospheric loss only at the vicinities of the impact point and the antipode. These induce 29\% loss of global atmospheres. (The mass added to the Earth by the impact of a Mars-sized impactor is neglected). Table 3 indicates $50 \%$ loss from the Earth requires slightly greater energies, $\sim 1.3 \times 10^{32} \mathrm{~J}$. We conclude, within the many approximations made, that a number of Mars-sized impactors are required to blow-off the entire Earth's atmosphere. Thus the present atmosphere could be only a remnant of the protoatmosphere that surrounded the Earth upon accretion $4.6 \times 10^{9}$ years ago.

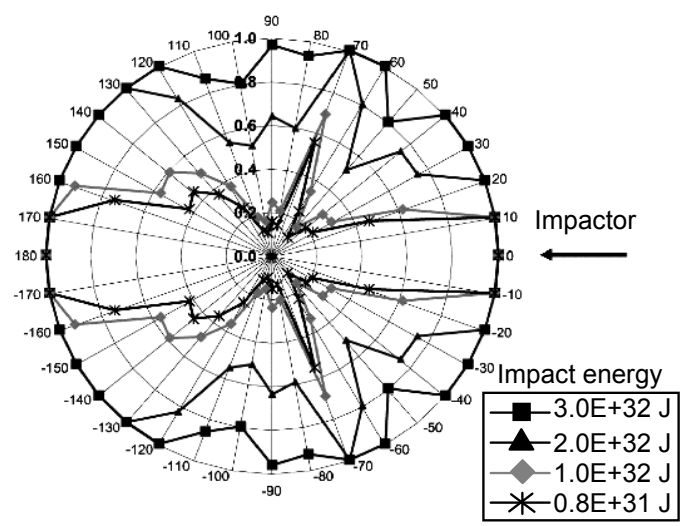

FIGURE 3. Fractional atmospheric loss versus angle from source, for different energies. 
TABLE 1. Planetary and atmospheric parameters used in model planets.

\begin{tabular}{lrrr}
\hline Parameters & Earth & Venus & \multicolumn{1}{c}{ Mars } \\
\hline Planet radius, $(\mathrm{km})$ & 6371 & 6052 & 3390 \\
\hline Specific heat ratio, $\gamma$ & 1.4 & 1.23 & 1.33 \\
\hline $\begin{array}{l}\text { Sound velocity, } \\
(\mathrm{m} / \mathrm{s})\end{array}$ & 340 & 416 & 234 \\
\hline $\begin{array}{l}\text { Base atmospheric } \\
\text { density, }\left(\mathrm{kg} / \mathrm{m}^{3}\right)\end{array}$ & 1.217 & 65 & 0.020 \\
\hline $\begin{array}{l}\text { Base atmospheric } \\
\text { pressure, (Pa) }\end{array}$ & $1.014 \times 10^{5}$ & $9.4 \times 10^{6}$ & 640 \\
\hline $\begin{array}{l}\text { Pressure at top of } \\
\text { model, }(\mathrm{Pa})\end{array}$ & 0.5 & 5.1 & $9.8 \times 10^{-3}$ \\
\hline $\begin{array}{l}\text { Atmosphere scale } \\
\text { height, } \mathrm{h}(\mathrm{km})\end{array}$ & 8.5 & 15.9 & 11.1 \\
\hline $\begin{array}{l}\text { Surface temperature, } \\
(\mathrm{K})\end{array}$ & 288 & 737 & 210 \\
\hline $\begin{array}{l}\text { Escape velocity, } \\
\mathrm{V}_{\text {esc }}(\mathrm{km} / \mathrm{s})\end{array}$ & 11.19 & 10.36 & 5.03 \\
\hline $\begin{array}{l}\text { Surface gravity, } \mathrm{g} \\
\left(\mathrm{m} / \mathrm{s}^{2}\right)\end{array}$ & 9.798 & 8.87 & 3.71 \\
\hline $\begin{array}{l}\text { Planetary mass, M } \\
\left(10^{24} \mathrm{~kg}\right)\end{array}$ & 5.97 & 4.87 & 0.642 \\
\hline
\end{tabular}

TABLE 2. Impact energies required for $50 \%$ atmospheric loss

\begin{tabular}{cc}
\hline Planet & $\begin{array}{c}\text { Impact Energy for 50\% } \\
\text { Atmospheric Loss }(\mathbf{J})\end{array}$ \\
\hline Earth & $1.3 \times 10^{32}$ \\
\hline Venus & $1.4 \times 10^{32}$ \\
\hline Mars & $1.0 \times 10^{29}$ \\
\hline
\end{tabular}

\section{ACKNOWLEDGEMENTS}

Research supported by NASA. Editorial suggestions proffered by M.D. Furnish are gratefully acknowledged. Contribution \# 8975, Division of Geological and Planetary Sciences, California Institute of Technology, Pasadena, CA 91125.

\section{REFERENCES}

1. Sato, Y., Usami, T., and Landisman, M., Bull. Earthquake Res. Inst. 45, 601-624 (1967).

2. Safronov, V. S., Evolution of the ProtoPlanetary Cloud and Formation of the Earth and Planets, Israel Prog. Scient. Transl., Jerusalem, (1972), pp. 200.

3. Wetherill, G. W., Ann. Rev. Earth Planet. Sci. 18, 205-256 (1990).

4. Kaula, W. M., J. Geophys. Res. 84, 9991008 (1979).

5. Smith, B. A. and Terrile, R. J., Science 226, 1421-1424 (1984).

6. Baggaley, W. J., J. Geophys. Res. - Space Phys. 105, 10353-10361 (2000).

7. Abe, Y. and Matsui, T., J. Geophys. Res. 90, C545-C559 (1985).

8. Lange, M. A. and Ahrens, T. J., Icarus 51, 96-120 (1982).

9. $\quad$ Fitzgerald, R., Phys. Today 56, 16-18 (2003).

10. Ahrens, T. J., in Origin of the Earth, edited by J. Jones and H. Newsom (Oxford U. Press, Oxford, 1990), pp. 211227.

11. Ahrens, T. J., Annu. Rev. Earth Planet. Sci. 21, 525-555 (1993).

12. Chen, G. Q. and Ahrens, T. J., Phys. Earth Planet. Inter. 100, Nos. 1-4, 21-26 (1997).

13. Genda, H. and Abe, Y., Icarus 164, 149162 (2003).

14. Melosh, H. J., Nature 424, 22-23 (2003).

15. Melosh, H. J. and Vickery, A. M., Nature 338, 487-489 (1989).

16. Newman, W. I., Symbalisty, E. M. D., Ahrens, T. J. et al., Icarus 138, 224-240 (1999).

17. Ni, S. and Ahrens, T. J., Geophys. J. Int. (submitted) (2003). 